\section{Confidence Returning}

Compared with many of its meetings in the sixties the Conference of Representatives of Local Medical Committees this year was a tranquil occasion. Nevertheless, some important issues were decided, notably a target date for instituting vocational registration and the acceptance of revised terms of service for N.H.S. family doctors. The mood of the Conference-the first part of the proceedings are reported in the Supplement (p. 172)-suggested that after the troubles of the past decade general practitioners are now recovering their collective self-confidence.

The meeting came close to overturning its policy that national insurance certification should be banished from the surgery, and various proposals that the Government should provide particular equipment or contribute more towards ancillary help were rejected. But some cogent arguments were made for retaining certification as an important part of the family doctor's work and several speakers during discussions involving money reminded their audience of the meaning-as well as the importance-of independence. Nevertheless, emotions broke through on two occasions: on the first day when the terms of service were being discussed, and again on Thursday when Dr. R. A. Keable-Elliott received a well-deserved ovation for his lucid exposition on N.H.S. superannuation.

The platform weathered the storm over the revisions that the G.M.S. Committee had agreed with the Government on terms of service with only one mild rebuff. Ever since it had been announced that the draft proposals (which were planned to form the substance of a Parliamentary statutory instrument) would have a restricted audience because of difficulties over Parliamentary privilege dissatisfaction had built up among some general practitioners. Though there was criticism of some of the contents of the revised terms of service the main argument was over their limited circulation and the alleged lack of time for discussion by local medical committees. For a man who for seven long years had hacked his way through the legal thickets of this thorny subject Dr. R. B. L. Ridge, Chairman of the Statutes and Regulations Subcommittee, was most restrained in replying to these criticisms. He pointed out that though his working party, which had had continuing expert legal advice, had invited comments and proposals from all local medical committees, only three had sent in detailed replies. There had been a few letters from others but most had been silent. In the event the Conference had it both ways by accepting the revised proposals, and appeasing the critics by agreeing to a proposal from Nottingham to invite a contract lawyer to prepare a model contract for N.H.S. family doctors for consideration.

The Conference passed another stage on the way to making vocational training a universal requirement for entering general practice. Stimulated by a report that the Common Market Permanent Commission of Doctors has recently proposed two years of voluntary vocational training for general practice-and by several strong speeches underlining the imoortance of vocational training for the future of family doctoring-the meeting asked the G.M S.C. to "make strenuous efforts to have sufficient schemes of vocational training for general practice introduced in order to ensure that, by a definite date, not later than 1977, vocational registration for general practice can be imolemented." This decision brings the policies of the Conference virtually into step with those of the Royal College of General Prac- titioners and will go a long way to ensuring that in time no doctor will be able to become a principal in general practice without three years of vocational training.

Items on pay took up to a quarter of the agenda, but they were discussed without any great heat. Dr. Cameron spoke of the impending Review Body report, there was criticism of Lord Halsbury's use of recommended net average income, and there were some exchanges about the proposed two-tier temporary resident fees which had been agreed by the G.M.S. Committee. But outside the holiday areas this latter topic obviously raises little enthusiasm. Pay has almost been overtaken by pensions in importance in this inflationary era, and the members paid close attention to the debates in this section. But, having been told of the G.M.S. Committee's efforts in the superannuation arena, they seemed quite prepared to leave the Committee to get on with laying continuing siege to the Government.

The Conference beavered away at several "old faithfuls" such as maternity services, mileage payments, cervical cytology, family planning, and the supply of oxygen equipment, though one-practice compensation-has at last been buried, or almost, for the necessary legislation is still awaited. Surprisingly, the hospital service attracted only a handful of motions, while the General Medical Council and the Common Market attracted none at all. No doubt L.M.C.s were satisfied with the G.M.S. Committee's report on its work in these important areas.

The Chambers Report, to be discussed at a special conference in November, was not even smuggled in by any procedural side doors, but the G.M.S. Committee's autonomy and general-practitioner representation figured in a motion in the section on N.H.S. reorganization. With only 11 motions (six of this group for debate) on reorganization representatives barely got to grips with this complex problem. Nevertheless, three special conferences have been held since 1969 and another might be necessary warned Dr. Cameron, though he seemed reasonably optimistic about the family doctor's position after 1974. No doubt this too was a subject which the meeting was willing to leave to the members of the G.M.S. Committee, who, Dr. Cameron reported, would soon be hearing from the Secretary of State in person. This unprecedented visit to the Committee undoubtedly reflects the importance the Government attaches to general practice, and no doubt it contributed a little to the atmosphere of quiet self confidence that pervaded the Conference.

\section{Rehabilitation Services}

The Tunbridge Committee, which reported ${ }^{1}$ last week after four years' consideration of the future of the rehabilitation services, frankly admits that there is a low level of interest in the subject among doctors, and that if its recommended expansion of these services occurs it may be difficult to attract both consultants and recruits to the training grades.

The report rightly stresses the wide need for rehabilitation units. Too many doctors seem to think of them only in connexion with permanent disablements such as amputations; in fact their major role should be in promoting rapid recovery of normal function after injury or illness. 
The report calls for an immediate expansion of rehabilitation services, which, it says, should come under the control of the Department of Health rather than the Department of Employment.

Regional boards, it suggests, should appoint medical advisers to review existing facilities and they should present proposals for future development to the Department by April 1973. Every district hospital should have a rehabilitation department under the charge of a consultant who "should devote a substantial part of his time to this work." He should also run an assessment clinic which should co-ordinate efforts within the hospital with those organized by the local authority. In another burst of realism, however, the report acknowledges that at present while there are 89 consultants in physical medicine in the metropolitan area there are only 42 in the rest of England and Wales. Clearly most new rehabilitation departments will have to be run by consultants in other specialties for many years to come-if they can be persuaded to take on the task.

For this is the problem. Specialist rehabilitation units for specific injuries and industrial rehabilitation units do valuable work, but the main need for rehabilitation is among the patients admitted to acute medical and surgical wards, $60 \%$ of whom are of pensionable age. These old folk can so easily lapse into invalidism if their medical attendants lose interest once the acute illness or injury has been coped with. The message of the Tunbridge report is that it is no longer good enough for the consultant physician to murmur to his houseman to "give the old thing a bit of physio." Rehabilitation must be seen as a specialty just as important and indeed needing as much specialist knowledge as any other. This change of attitude is essential if doctors are to be attracted into rehabilitation, and one way it might be encouraged is through the committee's proposal for some university chairs in the specialty. Despite the many other areas within the N.H.S. which need money this and other recommendations in the report should be supported, for it is surely right in saying that further neglect of this branch of medicine will be "destructive of the quality of people's lives."

1 Rehabilitation. Report of a Subcommittee of the Standing Medical Advisory Committee. London, H.M.S.O., 1972, price £1.

\section{Iron in Infancy}

Iron deficiency is still the commonest cause of anaemia in childhood, appearing most frequently between the ages of 6 months and 3 years. Forty years ago H. M. M. Mackay and L. Goodfellow' noted a declining haemoglobin level in infants between 6 and 15 months of life and in 1950 a similar pattern was reported by $M$. Horan. ${ }^{2}$ The anaemia in these infants was corrected by iron therapy. ${ }^{1}$

A recent study by D. Burman ${ }^{3}$ in Bristol showed some improvement, for the drop in haemoglobin concentration after six months no longer occurred. This suggests that the iron intake of the babies is better than it used to be. A marginally higher haemoglobin level in the second year of life was achieved in a group treated with $10 \mathrm{mg}$ iron by mouth daily, though further analysis showed that this effect was evident only in male infants in social classes I and II. Iron supplement did not give any apparent clinical benefit as assessed by weight gain or days of illness. Why infants from less affluent groups should have better iron stores was uncertain, but a disproportionate intake of iron-enriched cereals was suggested as a cause.

Inadequate diet and small iron stores at birth remain the commonest reasons for iron deficiency. The newborn, normal-term infant has about $250 \mathrm{mg}$ of iron, of which about $150 \mathrm{mg}$ is in haemoglobin. Body iron almost doubles in the first 12 months of life and more than doubles at 2 years. In the second 6 months of life the infant needs $0.9 \mathrm{mg}$ of iron each day and thereafter $0.5 \mathrm{mg}$. The diet supplies relatively little iron in the first few months of life, as human and cow's milk both contain only about $0.075 \mathrm{mg}$ iron per $100 \mathrm{~g}$. In the United Kingdom it has been estimated that at the end of the child's first year its daily iron intake is $8 \mathrm{mg}$ per day, with a slight fall in the second year. ${ }^{4}$ The values, however, cover a wide range, so that many infants are receiving less than the minimum daily needed-probably around $5 \mathrm{mg}$ - to provide sufficient iron. Like adults, infants absorb an average of $10 \%$ of dietary iron, through greater absorption occurs during the first year of life. ${ }^{5}$ Less affluent groups were not well represented in Burman's study, and children from these groups probably have insufficient iron during their second year. It would be unwise, therefore, to assume that in Britain iron therapy is now rarely needed in infancy.

In the United States I. Schulman ${ }^{6}$ noted that $44 \%$ of children between 6 months and 2 years had haemoglobin levels of less than $10 \mathrm{~g}$ per $100 \mathrm{ml}$, and in $15 \%$ the levels were less than $8 \mathrm{~g}$ per $100 \mathrm{ml}$. In Burman's study some $70 \%$ of the infants had haemoglobin levels above $10 \mathrm{~g}$ per $100 \mathrm{ml}$, and almost $95 \%$ had levels above $9.5 \mathrm{~g}$ per $100 \mathrm{ml}$. Iron deficiency is relatively unusual in children over 3 , and this, together with the lack of benefit of iron therapy at this stage, suggests that iron therapy is unnecessary unless the haemoglobin level is below $10 \mathrm{~g}$ per $100 \mathrm{ml}$. The Bristol study concludes that the routine administration of haematinic substances to infants is unlikely either to raise haemoglobin levels or to improve' the child's health. This underlines the importance of doing haemoglobin estimations before prescribing iron for infants.

\footnotetext{
1 Mackay, H. M. M., and Goodfellow, L., Medical Research Council, Special Report Series, 1931, No. 157.

2 Horan, M., Archives of Disease in Childhood, 1950, 25, 110.

3 Burman, D., Archives of Disease in Childhood, 1972, 47, 261.

4 Ministrv of Health, Reborts on Public Health and Medical Subjects, No. 118, p. 55. London, H.M.S.O., 1968.

5 Gorten, M. K., Hepner, R., and Workman, J. B., fournal of Pediatrics, $1963,63,1063$.

- Schulman, I., fournal of the American Medical Association, 1961, 175, 118.
} 